\title{
Chronic Leg Pain in Athlete Caused by Deep Peroneal Schwannoma, a Case Report
}

\author{
Tan Wei How, Wan Hazmy Che Hon \\ KPJ Healthcare University College, Negeri Sembilan, Malasia \\ Email: tanweihow@yahoo.com.my
}

How to cite this paper: How, T.W. and Hon, W.H.C. (2021) Chronic Leg Pain in Athlete Caused by Deep Peroneal Schwannoma, a Case Report. Journal of Biosciences and Medicines, 9, 38-43.

https://doi.org/10.4236/jbm.2021.97006

Received: June 12, 2021

Accepted: July 12, 2021

Published: July 15, 2021

Copyright $\odot 2021$ by author(s) and Scientific Research Publishing Inc. This work is licensed under the Creative Commons Attribution International License (CC BY 4.0).

http://creativecommons.org/licenses/by/4.0/

\begin{abstract}
Schwannomas are benign, well-encapsulated and slow growing tumor arising from Schwann cells of the peripheral nerve sheath. They commonly saw in the head and neck, rarely from deep peroneal nerve in the lower limb. We present a case of 42-year-old active national hockey coach, who presented with mild pain and numbness over lateral aspect of left leg for 2 years. The pain was provoked by sporting activities, and was initially relieved by analgesics, until recently, hence his presentation. MRI was done and showed well-defined oval lesion within the deep intermuscular fascia between tibialis anterior and extensor halluces longus muscles. He had an open dissection, and the histology showed a diagnosis of schwannoma. Post-operative healing was uneventful, the pain and numbness improving after 12 months.
\end{abstract}

\section{Keywords}

Benign, Deep Peroneal, Excisional Biopsy, Schwannoma

\section{Introduction}

Schwannomas, also known as Neurilemmoma are the most common benign tumors of the peripheral nerve, arising from schwann cell [1]. The condition usually presents in the 3rd to 6th decades of life with paresthesias in the distribution of peripheral nerve. Malignant transformation of the schwannoma is extremely rare [2]. It is often misdiagnosed with other common lesions like lipoma and fibroma due to lack of awareness [3]. The tumor is well encapsulated on the surface of a peripheral nerve, often occurs on flexor surfaces of extremities and head and neck. In lower limb, they usually occur in main nerve trunks, rarely in collateral branches of a nerve [4] [5]. It can affect motor or sensory nerves. The diagnosis of schwannoma usually inconclusive and incidentally found in sono- 
graphy, computed tomography, and magnetic resonace imaging examination. However, it can be confirmed by histopathological analysis of the operated specimen [6] [7]. We present a case of lateral leg pain in a professional athlete due to an atypical localization of schwannoma.

\section{Case Report}

A healthy 42 year-old gentleman, who is a national hockey coach. Informed consent for publishing the case was obtained from patient. Presented with progressive left leg pain for 2 year. The pain was sharp in nature and radiating from lateral aspect of the mid shin to the first webspace of the left foot. It was associated with numbness over the first webspace of the left foot. The pain was aggravated by sport activities. He had multiple visits to his panel doctor and treated as muscle sprain and pain management and physiotherapy were temporary relieved his symptoms. On examination, there was vague mass palpable over lateral aspect of the left leg at mid shin level (Figure 1). It was firm in consistency and mild tenderness on palpation. The ankle range of motion was normal except dorsiflexion reduced from 0 - 15 degree.

MRI of the left leg (Figure 2(a) and Figure 2(b)) showed there is a well-defined oval lesion measuring about $1.8 \times 3.2 \mathrm{~cm}$ within the deep intermuscular fascia between tibialis anterior and extensor halluces longus muscles. The features are likely to represent peripheral nerve sheath tumor with differential diagnosis of myxoma or hemangioma.

In view of the chronicity of the leg pain and conservative management failed, he decided to proceed with surgical removal of the mass. Intra-operatively, incision made overlying the mass around $6 \mathrm{~cm}$ into fascia. Exploration in between tibialis anterior muscle and extensor hallucis longus muscles reviewed a well defined margin mass. The mass arising from the deep peroneal nerve (Figure 3). The mass was able to remove with minimal dissection of the deep peroneal nerve and no nerve repair was required (Figure 4).

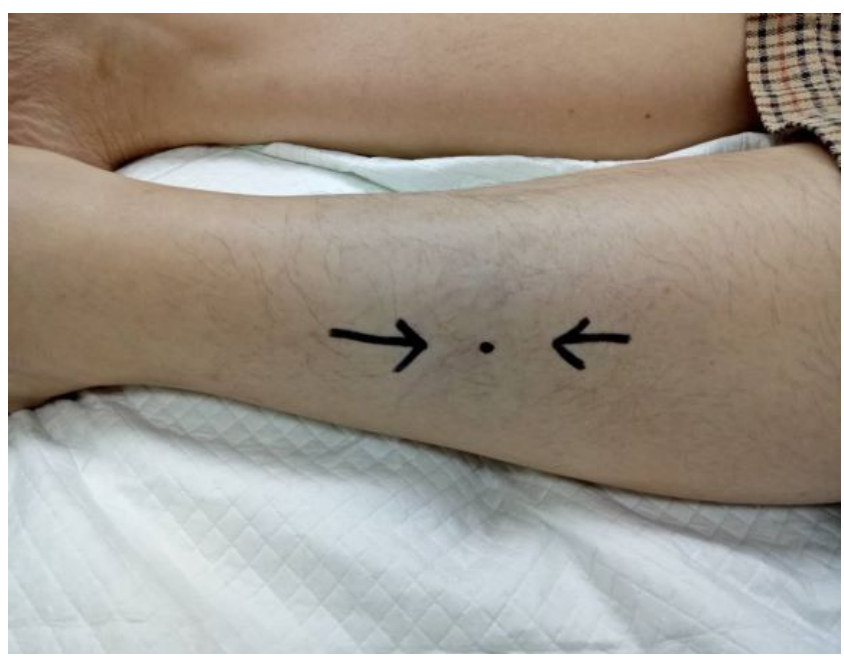

Figure 1. Vague mass palpable over lateral aspect of left leg. 


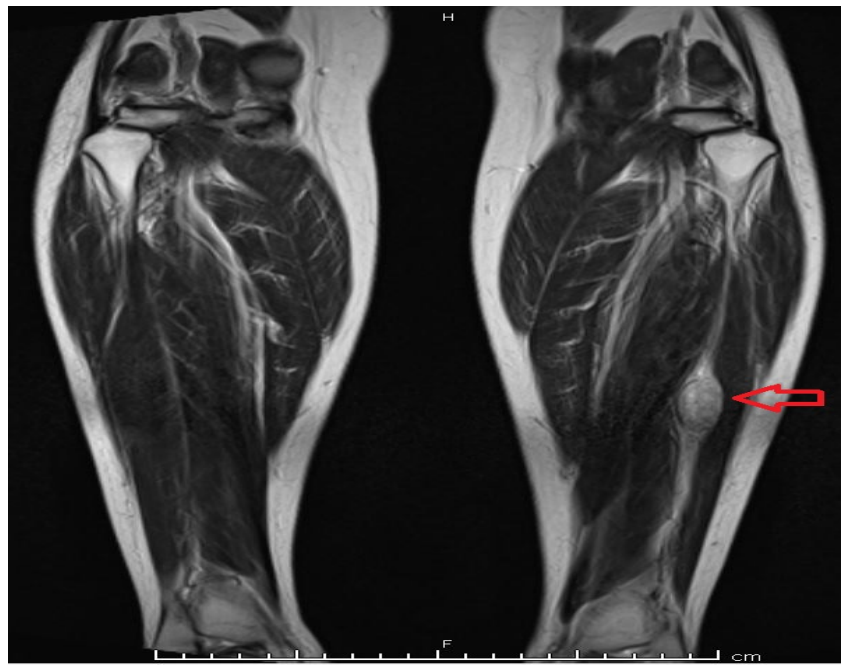

(a)

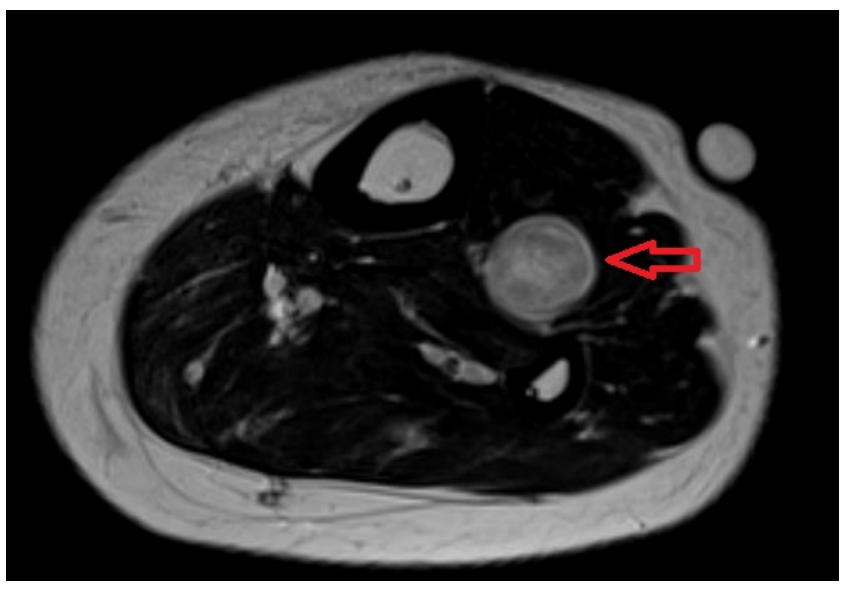

(b)

Figure 2. (a) and (b) MRI of the left leg showed there is a well-defined oval lesion (red arrow) within the deep intermuscular fascia between tibialis anterior and extensor halluces longus muscles.

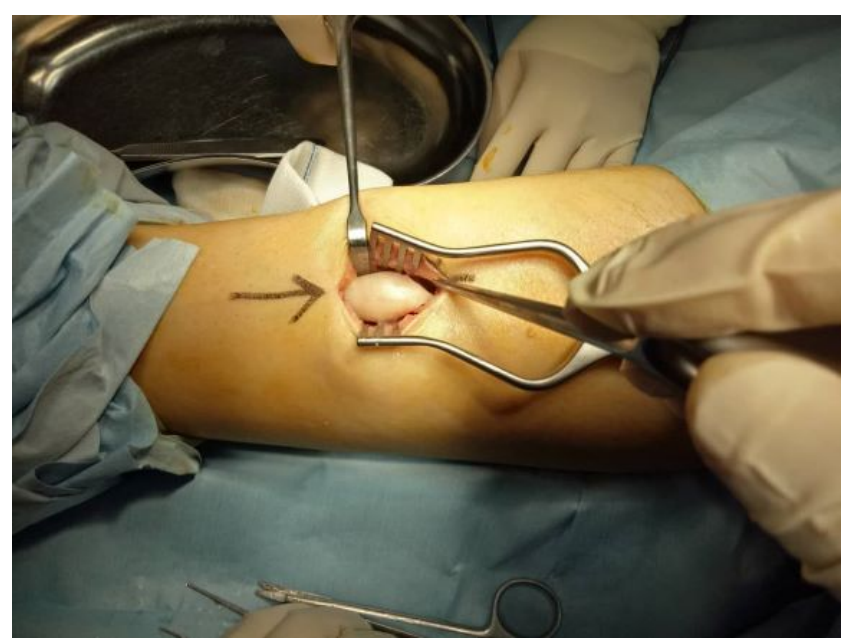

Figure 3. There was a mass arising from the deep peroneal nerve. 


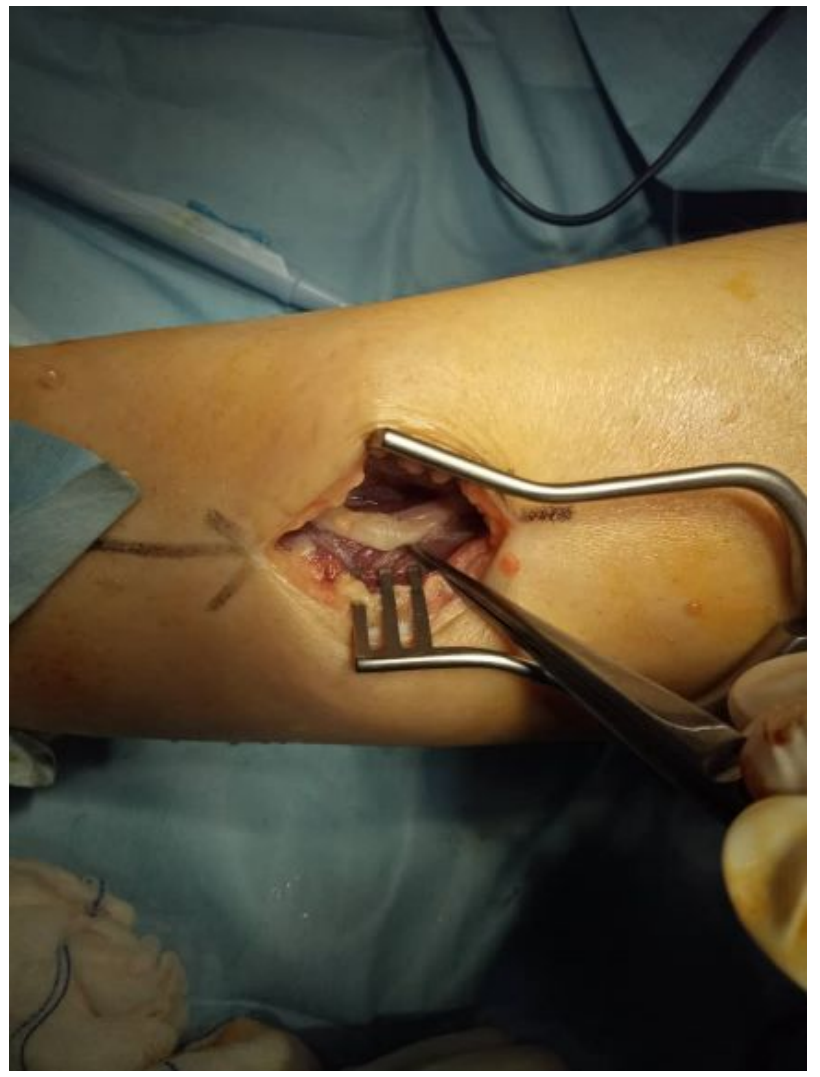

Figure 4. Deep peroneal nerve still intact after removal of the mass.

The mass was send for histopathology examination (Figure 5). The HPE report showed encapsulated spindle cell tumor composed of hypo and hypercellular areas. The hypercellular areas shows tumor cells in nuclear pallisading pattern interspersed with collagen fibers, features of schwannoma with no evidence of malignancy (Figure 6).

Post operatively, the leg pain improved but numbness of the foot remained. During follow up after 3 months, the numbness improving and tinel\$ sign positive along the nerve pathway. 12 months post-surgery, the ankle dorsiflexion improved to 0 - 30 degree and numbness subsided.

\section{Discussion}

Chronic leg pain is the commonest complaints in athletes [8]. The main etiologies of the leg pain include chronic exertional compartment syndrome, medial tibial stress syndrome, tibial stress fracture, Archilles tightness, myxomapopliteal artery entrapment syndrome, nerve entrapment, complex regional pain and deep vein thrombosis [8] [9]. Our case presented with atypical localization of schwannoma at deep peroneal nerve causing chronic leg pain, which initially misdiagnosed as muscle sprain. Although schwannomas represent the commonest bnign peripheral nerve sheath tumors, the occurrence on the lower limbs account for $1 \%$ of all case [10]. Radiology modalities like sonography, CT scan and MRI may help in detecting this benign tumor, but they are not possible to 


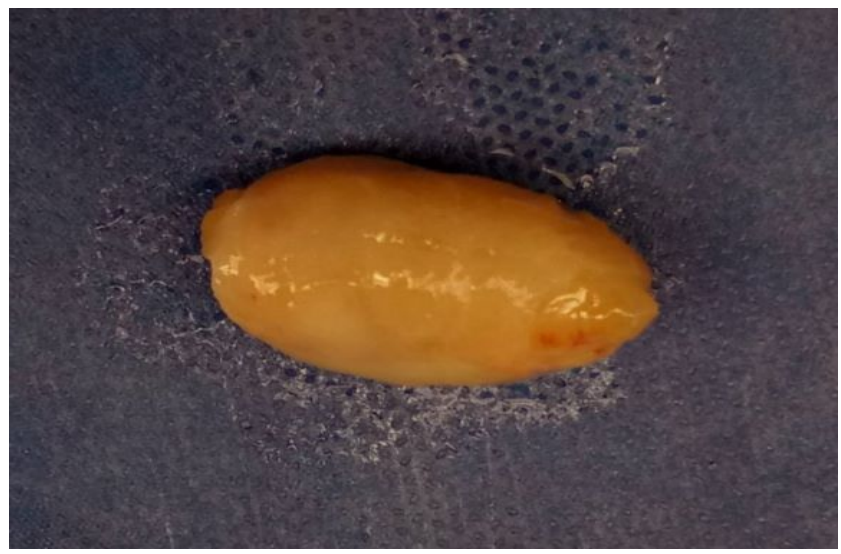

Figure 5. Specimen with nodular tissue measuring $3 \times 1.5 \times 1.5$ $\mathrm{cm}$ sent for HPE.

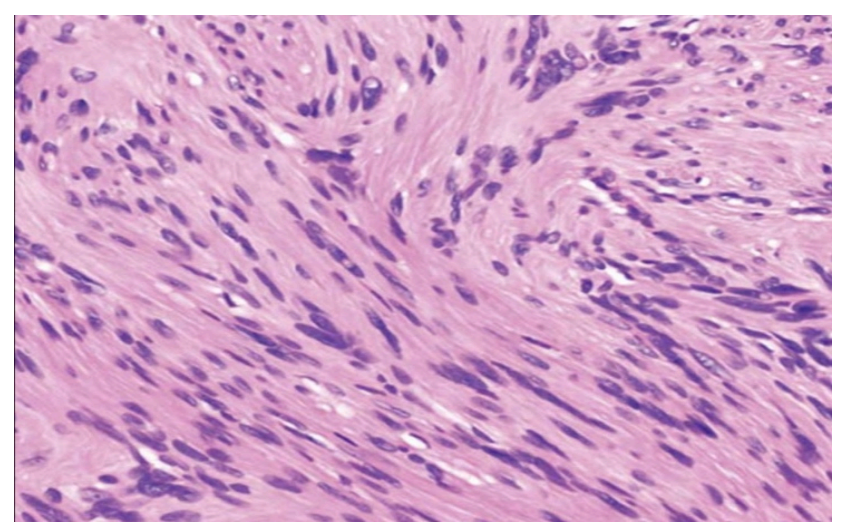

Figure 6. HPE reported encapsulated spindle cell tumor composed of hypo and hypercellular areas. The hypercellular areas shows tumor cells in nuclear pallisading pattern interspersed with collagen fibers.

differentiate with other benign or malignant tumor with same consistency such as ganglion, lipoma, myxoma, neurofibroma or malignant peripheral nerve sheath tumor [11]. Hence, histopathology examination of the specimen is very important. Small solitary schwannoma can be managed conservatively. Surgical dissection indicated if there is progressive neurological deficit, persistent pain, suspicious of malignancy or progressive growing in size. Schwannoma can be dissected carefully from the parenting nerve without injury to the continuity of the nerve because this tumor seldom invaginates into the nerve [12]. Thus, loss of nerve function post surgery is rare. In our case, we managed to dissect the schwannoma completely from the deep peroneal nerve without compromised the nerve function, in fact it improved after surgery because of free from the tumor compression.

\section{Conclusion}

Schwannomas originating from the lower limb are rare but they should be suspected in chronic leg pain patient especially those with numbness or weakness. 
Simple radiology modalities may support with the clinical findings and final histopathology confirmation is needed post surgery.

\section{Conflicts of Interest}

The authors declare no conflicts of interest regarding the publication of this paper.

\section{References}

[1] Adani, R., Tarallo, L., Mugnai, R. and Colopi, S. (2014) Schwannomas of the Upper Extremity: Analysis of 34 Cases. Acta Neurochirurgica, 156, 2325-2330. https://doi.org/10.1007/s00701-014-2218-2

[2] Rober, P.E. et al. (1991) Malignant Peripheral Nerve Sheath Tumor (Malignant Schwannoma) of Urinary Bladder in Von Recklinghausen Neurofibromatosis. Urology, 38, 473-476. https://doi.org/10.1016/0090-4295(91)80242-Y

[3] Kapoor, R. and Saxena, B.R. (2018) Case Series of Peripheral Nerve Sheath Tumours: Schwanoma. Journal of Clinical and Diagnostic Research, 12, PR01-PR03. https://doi.org/10.7860/JCDR/2018/35340.11973

[4] Jerzy, G., Roman, R. and Jerzy, R. (2004) Peripheral Nerve Tumours in Own Materials. Folia Neuropathologica, 42, p.5.

[5] Mahajan, M., Sharma, R., Sharma, P. and Gupta, A. (2014) Schwannoma of Superficial Peroneal Nerve; Case Study. Journal of the American Podiatric Medical Association, 104, 539-543.

[6] Lee, J.A. and Boles, C.A. (2004) Peripheral Schwannoma Lacking Enhancement on MRI. American Journal of Roentgenology, 182, 534-535. https://doi.org/10.2214/ajr.182.2.1820534

[7] Pino, C., Ghazle, H., Bhatt, S. and Dogra, V. (2010) Schwannoma of ht Etibia Nerve. Journal of Diagnostic Medical Sonography, 26, 205-208. https://doi.org/10.1177/8756479310374360

[8] Pell IV, R.F., Khanuja, H.S. and Cooley, R.G. (2004) Leg Pain in the Running Athlete. Journal of the American Academy of Orthopaedic Surgeons, 12, 396-404. https://doi.org/10.5435/00124635-200411000-00004

[9] Burrus, M.T., Werner, B.C., Starman, J.S., et al. (2015) Chronic Leg Pain in Athletes. The American Journal of Sports Medicine, 43, 1538-1547. https://doi.org/10.1177/0363546514545859

[10] Rafai, M.A., El Otmani, H., Bouhaarajaj, F.Z., Largab, A. and Trafeh, M. (2006) Peroneal Nerve Schwannoma Presenting with a Peronel Palsy. Revue Neurologique, 162, 866-868. https://doi.org/10.1016/S0035-3787(06)75092-5

[11] Phalen, G.S. (1976) Neurilemmomas of the Forearm and Hand. Clinical Orthopaedics, 1976, 219-222. https://doi.org/10.1097/00003086-197601000-00024

[12] Gopal, A. (2017) Benign and Malignant Tumors of the Peripheral Nerve. In Youmans and Winn Neurological Surgery, 7 Edition, Chapter 258, Elsevier, Amsterdam. 